\title{
Single Phase Grid-Connected Inverter for Photovoltaic System with Maximum Power Point Tracking
}

\author{
Almas Hossain Mollah ${ }^{1}$, Prof. G KPanda ${ }^{2}$, Prof. P KSaha ${ }^{3}$ \\ PG Scholar, Dept. of Electrical Engineering, Jalpaiguri Government Engineering College, Jalpaiguri, West Bengal, \\ India $^{1}$ \\ HOD and Professor, Dept of EE, JGEC, Jalpaiguri, West Bengal, India ${ }^{2}$ \\ Professor, Dept of EE, JGEC, Jalpaiguri, West Bengal, India ${ }^{3}$
}

\begin{abstract}
This paper proposes a single-phase two stage inverter for grid-connected photovoltaic systems for residential applications. This system consists of a switch mode DC-DC boost converter and a H-bridge inverter. The switching strategy of proposed inverter consists with a combination of sinusoidal pulse width modulation (SPWM) and square wave along with grid synchronization condition. The performance of the proposed inverter is simulated under grid-connected scenario using MATLAB. Furthermore, the intelligent PV module system is implemented using a simple maximum power point tracking (MPPT) method utilizing power balance is also employed in order to increase the systems efficiency.
\end{abstract}

KEYWORDS: Photovoltaic; DC-DC Boost Converter; MPPT;SPWM; Square Wave; Power Electronics; Grid Tie Inverter(GTI)

\section{I.INTRODUCTION}

In the present scenario of world energy sector renewable sources are growing their importance day by day. This is mainly because of limited resource and bad environmental impacts of the conventional energy. Among the all renewable energy resources available, solar energy seems to be a major competitor as it is abundant in nature and its conversion to electricity through photovoltaic (PV) process is pollution-free. Increasing interest in PV systems, demands growth in research and development activities in various aspects such as Maximum Power Point Tracking (MPPT), PV arrays, anti-islanding protection, stability and reliability, power quality and power electronic interface. With increase in penetration level of PV systems in the existing power systems, these issues are expected to become more critical in time since they can have remarkable impact on the overall system performance. More efficient and cost-effective PV modules are being developed and manufactured, in response to the concerns raised by the PV system developers, utilities and customers.

Tracking the maximum power point (MPP) of a photovoltaic (PV) array is usually an essential part of a PV system. As such, many MPP tracking (MPPT) methods have been developed and implemented. The overall simplicity and efficiency of PV system depends on the MPPT technique employed. Various alternatives architectures for grid connected PV system configurations are available, such as centralized module, AC module and modular configuration where the last topology perfectly fits with an intelligent PV module concept. The AC module configuration, which is a simplified version of the centralized inverter topology. Here a single string of PV module is connected with an inverter. Each string can be applied with a separate MPPT, as there is no loss attributed to string diodes. In comparison to the centralized inverter the overall efficiency is increased. A common inverter is joined with multiple strings connected to individual DC-DC converter. The benefit of this modular configuration over centralized system is that each string can be controlled individually and ensure less cabling loss thereby enhancing the overall system efficiency.

Therefore, we proposed a two-stage intelligent PV system, which is similar to modular configuration topology. In an intelligent PV module instead of interconnection between modules they are interconnected with associated DCDC 


\section{(9) \\ ISSN (Print) : 2320 - 3765 \\ ISSN (Online): 2278 - 8875 \\ International Journal of Advanced Research in Electrical, Electronics and Instrumentation Engineering}

(An ISO 3297: 2007 Certified Organization)

\section{Vol. 4, I ssue 2, February 2015}

converter for MPPT tracking which ensures optimal operations of PV module. Various MPPT algorithms exist in different literatures. In this research, we propose perturb and observe $(\mathrm{P} \& \mathrm{O})$ method to extract maximum possible power from solar panel. In this article, a two-stage PV system is proposed which consists of a DC-DC boost converter with MPPT, and a DC-AC inverter to convert photovoltaic DC voltage into line $50 \mathrm{~Hz}$ AC voltage as shown in Fig. 1.2. In order to minimize the switching losses and to achieve better performance of the inverter, a combination of SPWM and a square wave signal is used for switching the inverter circuit.

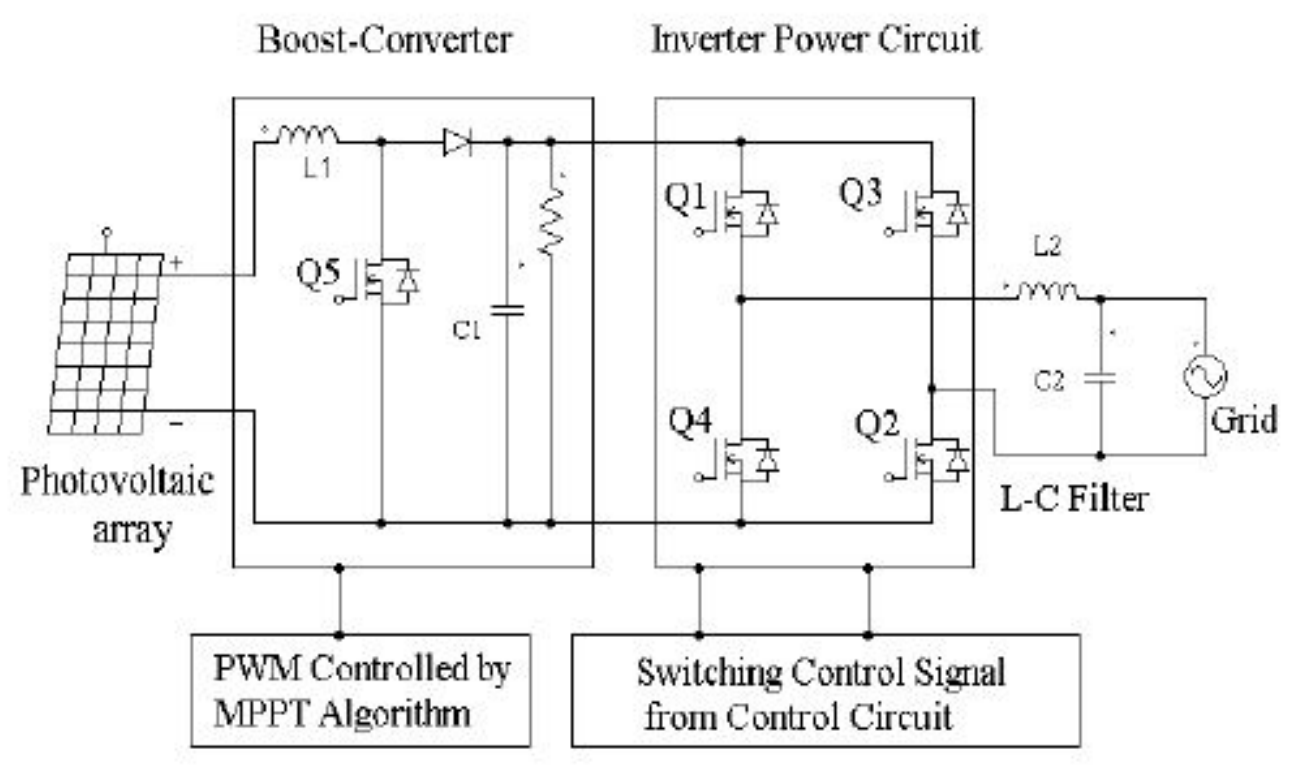

Fig.1 Block diagram of two-stage grid-connected PV system

Fig.1 shows diagram of two-stage grid-connected PV system

\section{MODEL OF PHOTOVOLTAIC}

$\mathrm{PV}$ array is made of p-n junction semiconductors that convert sunlight into electricity. Photons are absorbed to produce electricity when incoming solar energy exceeds band gap energy of the PV module. The I-V characteristic also known as current voltage relationship is a complex non-linear function. Several mathematical models exist to describe behavior of the solar panel. In this paper the following model is used for describing the photovoltaic panel

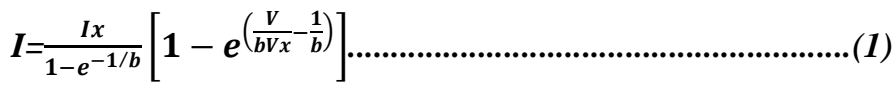

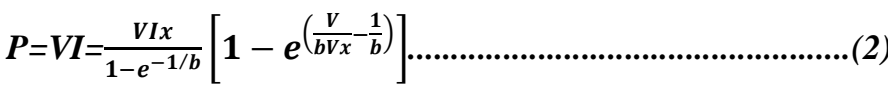

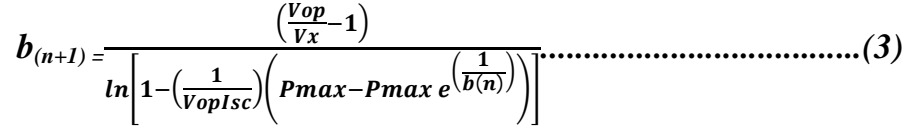

where, $I x$ is the short circuit current under Standard Test Conditions (STC), and $V x$ is the open circuit voltage under STC, and $b$ is the characteristic constant of the panel and can be approximated by equation (3) with Vop is the voltage at

which the maximum power is extracted from the panel and Pmax is the maximum power point of the panel, all under STC.The proposed inverter design is used an intelligent PV module concept that includes a DC-DC converter with MPPT controller. 


\title{
2 \\ ISSN (Print) : $2320-3765$ \\ ISSN (Online): 2278 - 8875 \\ International Journal of Advanced Research in Electrical, Electronics and Instrumentation Engineering
}

\author{
(An ISO 3297: 2007 Certified Organization) \\ Vol. 4, I ssue 2, February 2015 \\ III. CONTROL STRATEGY OF MPPT BASED ON DC-DCBOOST CONVERTER
}

\begin{abstract}
A.MPPT
A typical solar panel converts only 30 to 40 percent of the incident solar irradiation into electrical energy. Maximum power point tracking technique is used to improve the efficiency of the solar panel. According to Maximum Power Transfer theorem, the power output of a circuit is maximum when the Thevenin impedance of the circuit (source impedance) matches with the load impedance. Hence our problem of tracking the maximum power point reduces to an impedance matching problem. In the source side we are using a boost convertor connected to a solar panel in order to enhance the output voltage so that it can be used for different applications like motor load. By changing the duty cycle of the boost converter appropriately we can match the source impedance with that of the load impedance.
\end{abstract}

The Perturb \& Observe algorithm states that when the operating voltage of the PV panel is perturbed by a small increment, if the resulting change in power $\Delta \mathrm{P}$ is positive, then we are going in the direction of MPP and we keep on perturbing in the same direction. If $\Delta \mathrm{P}$ is negative, we are going away from the direction of MPP and the sign of perturbation supplied has to be changed

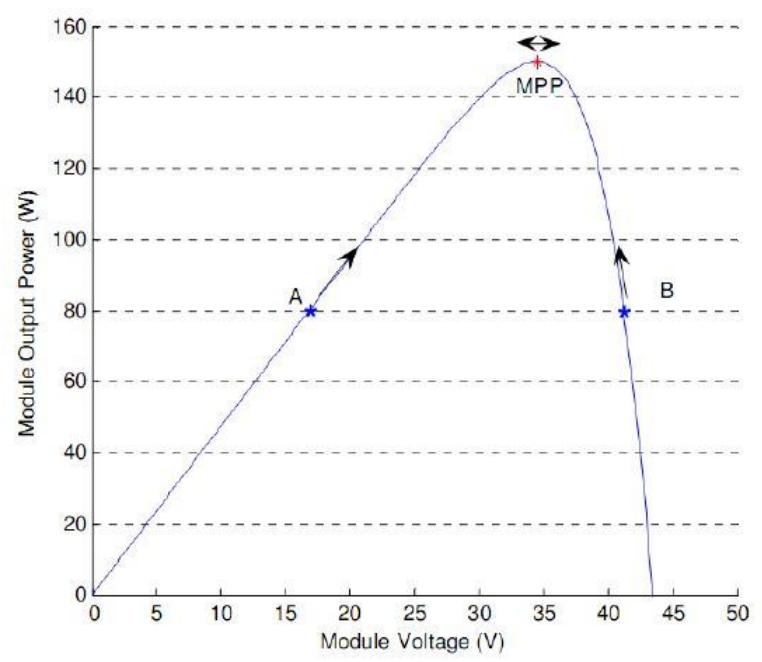

Fig.2 Solar panel characteristics showing MPP and operating points A and B

Fig.2 shows the plot of module output power versus module voltage for a solar panel at a given irradiation. The point marked as MPP is the Maximum Power Point, the theoretical maximum output obtainable from the PV panel. Consider A and B as two operating points. As Fig.2 shown in the figure above, the point A is on the left hand side of the MPP. Therefore, we can move towards the MPP by providing a positive perturbation to the voltage. On the other hand, point $\mathrm{B}$ is on the right hand side of the MPP. When we give a positive perturbation, the value of $\Delta \mathrm{P}$ becomes negative, thus it is imperative to change the direction of perturbation to achieve MPP.

\section{B. DC-DC Converter}

Switched mode DC-DC converter converts unregulated DC input voltage into regulated DC output voltage at a specified voltage level. Switching power supplies offer much more efficiency and power density compare to linear power supplies . Basic converters that step up or step down voltage input contains elements like transistors, diodes, capacitor and inductors. Three basic converter topologies exist, they are buck (step-down), boost (step-up) and buckboost (step-up or step-down). In our proposed design boost topology is used because its free wheeling diode can be used for blocking reverse current and it efficiently amplify PV arrays output voltage into higher level. Fig. 4 shows the output response of boost converter, which clearly indicates that, the intelligent PV system with MPPT function increase the output power from solar PV drastically. Converters are controlled by pulse width modulation (PWM) duty cycle since the output of converter being determined by state of transistor switch. Thus optimum load impedance of PV module is achieved by varying duty cycle. 


\section{International Journal of Advanced Research in Electrical, Electronics and Instrumentation Engineering}

(An ISO 3297: 2007 Certified Organization)

Vol. 4, I ssue 2, February 2015

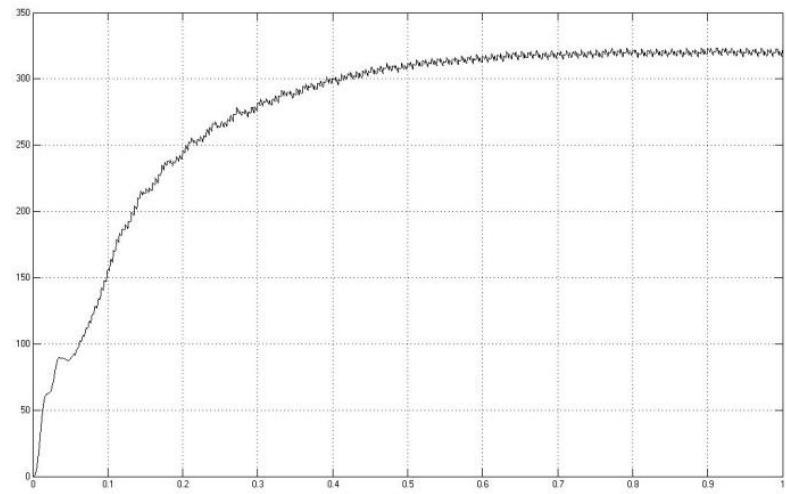

Fig.3 DC-DC Boost converter's output

Fig.3shows DC-DC Boost converter's output. Output of converter become constant to 312V .

\section{PROPOSED INVERTER DESIGN}

\section{A. Power Circuits}

The schematic circuit diagram of the proposed inverter, which consists of a DC-DC boost converter and a DC-AC inverter, is shown in Fig. 3. A DC-DC boost converter is employed to step up photovoltaic (PV) output voltage 24V DC into 312V DC that is shown in Fig. 4. The use of boost converter in our proposed design ensures high voltage gain from PV array voltage, and it has several advantages like lightweight, high efficiency etc. This inverter power circuit design contains a pair of two parallel MOSFET gates. The control circuit combines an analog circuit. Analog circuit is used to produce switching signal for inverter power circuit.

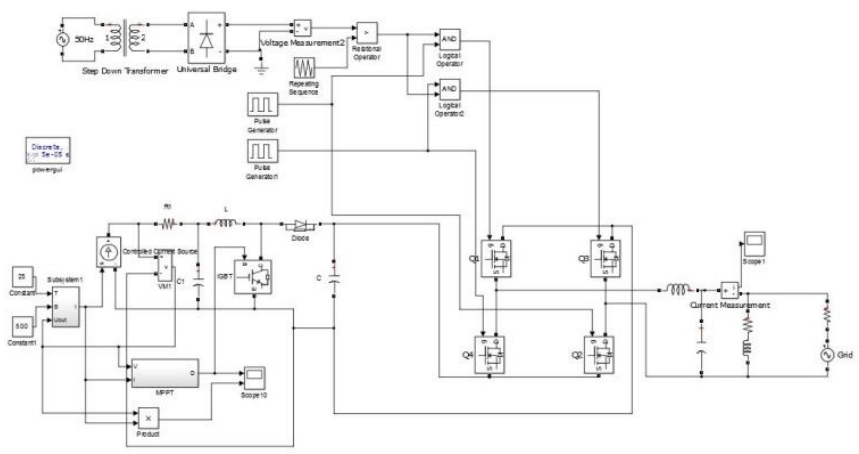

Fig. 4 Block diagram of grid connected PV inverter for simulation in MATLAB

Fig. 4 represents Block diagram of grid connected PV inverter for simulation in MATLAB

B. Switching/Control circuit

In conventional inverters only one type of switching technique is used. This proposed design instead uses a combination of SPWM and square wave to reduce the switching loss by reducing the switching frequency. Fig. 5 shows the proposed switching circuit of the grid-tie inverter (GTI). For the simplicity an analog oscillator or digital to analog converter (DAC) is omitted, instead the sine wave is sampled from power grid by using transformer that steps down voltage from $220 \mathrm{~V}$ to $5 \mathrm{~V}$. The sine wave sampled is used to generate the SPWM signal thus ensuring output voltage from GTI will have same frequency as the grid. After sampling, the sine wave is rectified with a precision rectifier, the output of which is shown in Fig. 6 


\section{International Journal of Advanced Research in Electrical, Electronics and Instrumentation Engineering}

(An ISO 3297: 2007 Certified Organization)

\section{Vol. 4, I ssue 2, February 2015}

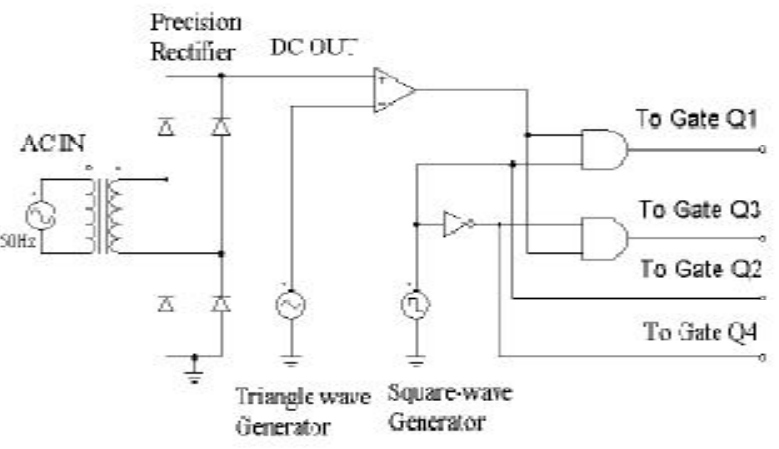

Fig. 5 Control circuit of proposed inverter design

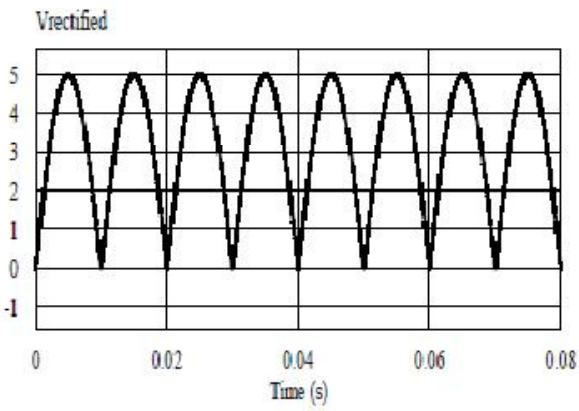

Fig. 6 Rectified sine wave

In addition, a high frequency triangle wave of $10 \mathrm{KHz}$ frequency is used. Then the two signals are passed through a comparator to produce the SPWM signal as shown in Fig. 7. A square wave signal is used as the line frequency $(50 \mathrm{~Hz}$ for India) and is in phase with the SPWM as shown in Fig. 8. The square wave is transmitted through a NOT gate to produce a signal that is 180 degree out of phase of the original Signal

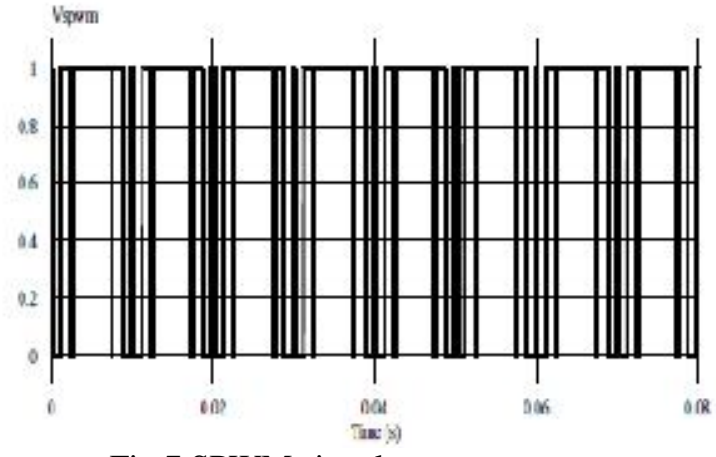

Fig.7 SPWM signal

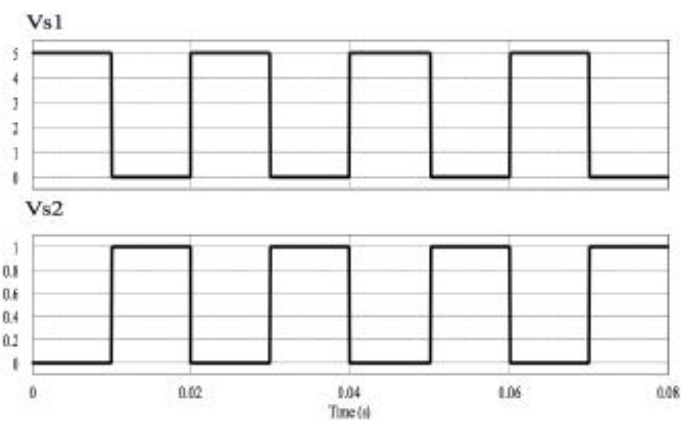

Fig.8 Square wave signal

The inverter requires four switching signals since it has four MOSFET switches. To create four signals an AND operation is performed between two sets of square wave signals and the SPWM. The four sets of switching signals can be categorized in two groups. The first group contains MOSFETs $\mathrm{Q}_{1} \& \mathrm{Q}_{2}$ while the second group contains MOSFETs $\mathrm{Q}_{3} \& \mathrm{Q}_{4}$. The gate pulses for switching of MOSFETs are illustrated in Figs.9. When $\mathrm{Q}_{2}$ is turned ON, $\mathrm{Q}_{1}$ is switched with SPWM signal and both $\mathrm{Q}_{3}, \mathrm{Q}_{4}$ are turned OFF. This creates positive output voltage at inverter. For negative part of output voltage $\mathrm{Q}_{1}$ and $\mathrm{Q}_{2}$ are forced to be $\mathrm{OFF}$ and $\mathrm{Q}_{4}$ is $\mathrm{ON}$ while $\mathrm{Q}_{3}$ is switched by SPWM.

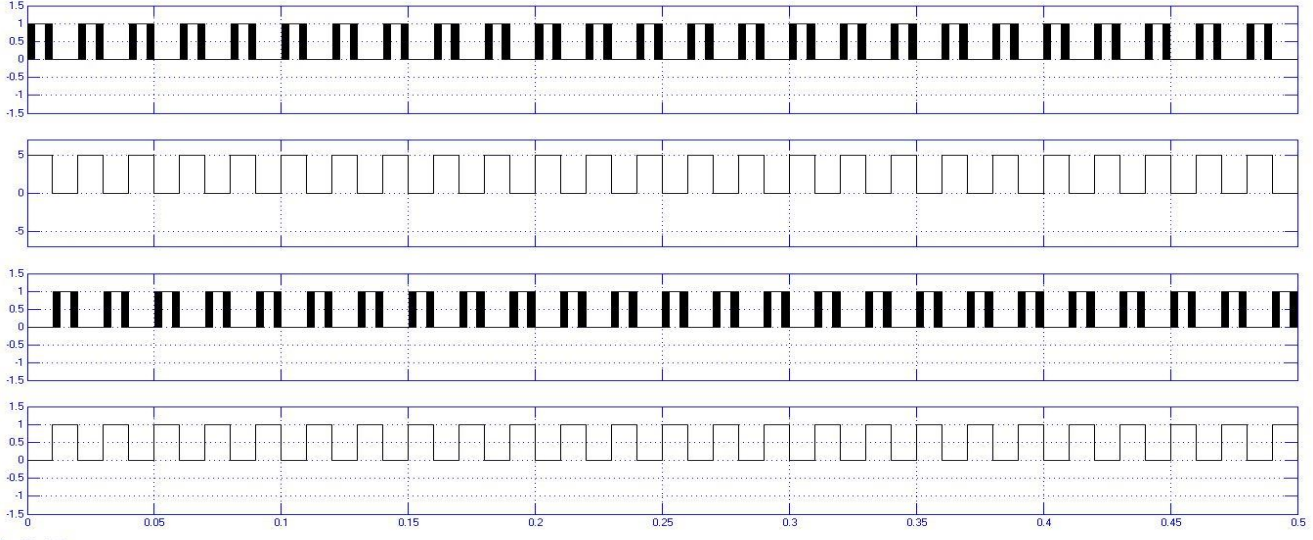

Fig.9 Switching signal from control circuit for MOSFET Q1,Q2,Q3,Q4 


\section{9 \\ International Journal of Advanced Research in Electrical, Electronics and Instrumentation Engineering}

(An ISO 3297: 2007 Certified Organization)

Vol. 4, I ssue 2, February 2015

\section{Design Operations of GTI}

Inverter operation can be divided into two parts: First part is synchronizing and the second part is power transmitting. During synchronization, the inverter will produce the output in phase with the grid. This is performed by sampling the sine wave and setting phase shift to zero. This un-shifted sine wave is rectified and compared with high frequency triangle wave to generate SPWM signal. An AND operation is performed between the SPWM and the square wave signal to produce four sets of switching signal. With this type of switching and zero phase shifts occurring the inverter output voltage will be controlled by the same phase as the grid. With inverter and grid voltage in phase the zero crossing of both voltages is detected. Once zero crossing is found contact between grid and inverter is activated and connects the grid and inverter together. After both voltages are connected the inverter begins to transmit power into the grid. In situations where the grid is down (off), the circuit breaker between grid and inverter trips. This prevents the grid having power from the inverter when it is down and cause unwanted accidents. The circuit breaker is shunt tripped by relay, which censors the grid with a current transformer (CT). After the grid loses power the relay activates and shunt trips the circuit breaker.

\section{SIMULATION RESULTS}

The proposed inverter is simulated using MATLAB software to verify the operation. The switching frequency is fixed at $10 \mathrm{kHz}$. The boost converter circuit step up $24 \mathrm{~V}$ PV arrays output into $312 \mathrm{~V} \mathrm{DC}$ and the inverter convert it into sinusoidal ac voltage. Since, we eliminate the use of line frequency transformer at the inverter output terminal and thereby it reduced additional power losses. Fig. 10 shows the output voltage without filtering. The simulation result shows that the output voltage of the inverter is distorted, non-sinusoidal, and contains harmonic that occurs additional power losses.

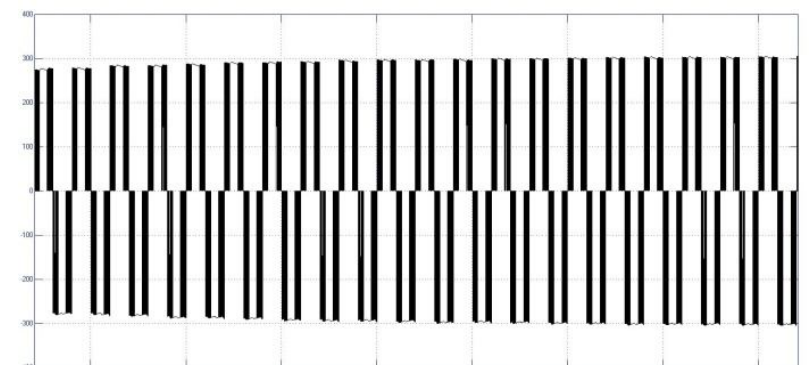

Fig.10 Output voltage of the inverter without filtering

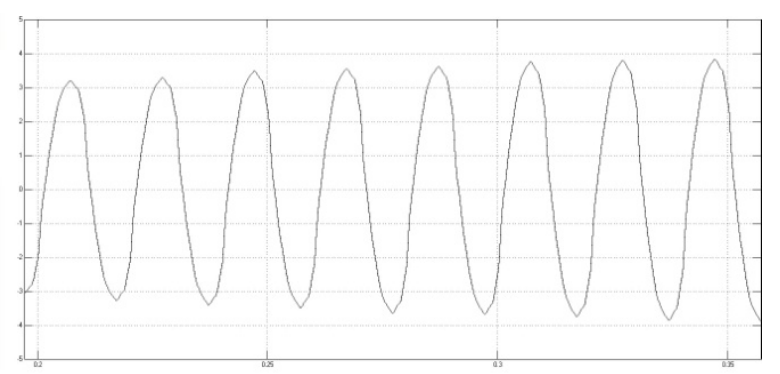

Fig.11 Output current of the inverter

A low pass L-C filter is employed in order to eliminate harmonic influence in output waveform. After filtering we obtain a better sinusoidal output waveform that is similar our grid. Fig. 11 shows output current waveform of our proposed grid-connected inverter. Fig. 12 shows the sinusoidal output voltage waveform $220 \mathrm{~V} \mathrm{rms} \mathrm{and} 50 \mathrm{~Hz}$ after connecting the inverter to grid line. It is observed that the total harmonic distortion (THD) of $7.03 \%$. Before filtering THD was $46.21 \%$. When inverter is connected to grid it takes few second to become stable. This transition period is caused by sudden addition of power into the grid. The magnitude and period of this transition current depends on impedance of power grid.

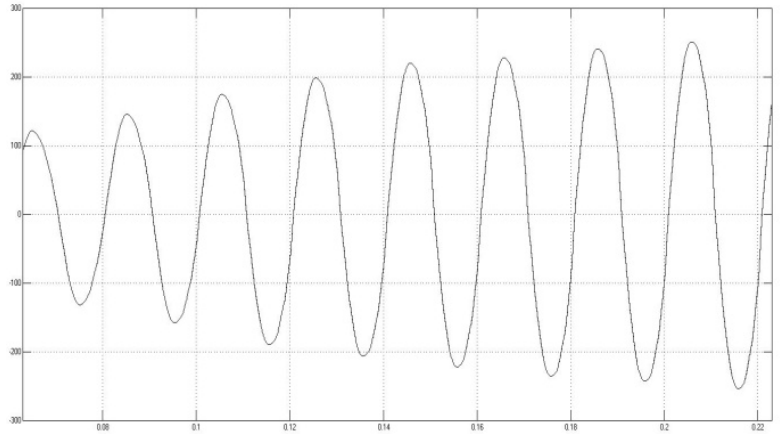

Fig.12 Output voltage after connected to grid

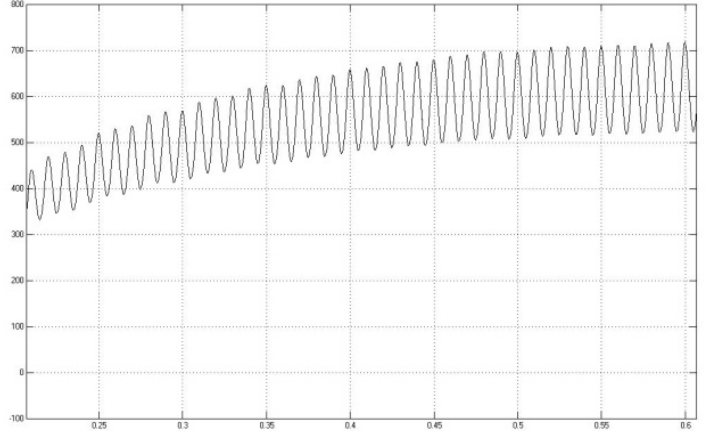

Fig.13. Output real power 
 \\ International Journal of Advanced Research in Electrical, Electronics and Instrumentation Engineering}

(An ISO 3297: 2007 Certified Organization)

\section{Vol. 4, I ssue 2, February 2015}

Fig. 13 shows the output real power of GTI. On the transition period the real power will fluctuate a lot and the real power come stable near at $700 \mathrm{~W}$.
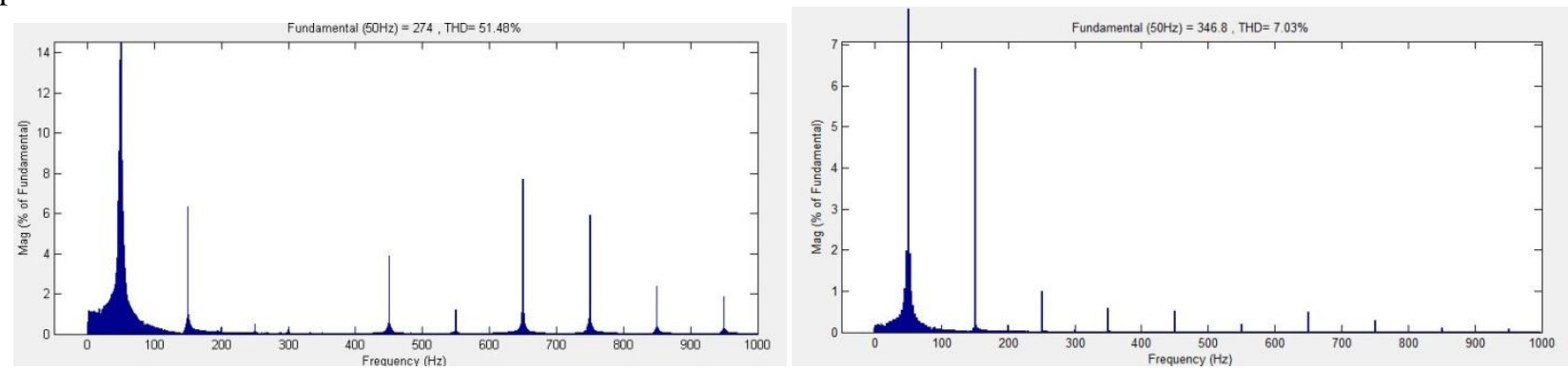

Fig.14. Output voltage's FFT (a) before filtering and (b) after filtering

Fig. 14 shows the First Fourier Transform (FFT) of output voltage (a) before filtering and (b) after filtering. FFT demonstrates that before filtering fundamental harmonics component lies at $50 \mathrm{~Hz}$ and also contains additional harmonics spectra. But after filtering FFT demonstrates that the fundamental harmonic component lies at $50 \mathrm{~Hz}$ and rest of the harmonic components are negligible

\section{VII.CONCLUSION}

The main purpose of this paper is to establish a model for the grid-connected photovoltaic system with maximum power point tracking function for residential application. A single phase two-stage grid-connected photovoltaic inverter with a combination of SPWM and square-wave switching strategy is designed using MATLAB. In the proposed design, an MPPT algorithm using a boost converter is designed to operate using $(\mathrm{P} \& \mathrm{O})$ method to control the PWM signals of the boost converter, which is adapted to the maximum power tracking in our PV system. Instead of using line frequency transformer at the inverter output terminals, a DC-DC boost converter is used between solar panel and inverter that efficiently amplify the $24 \mathrm{~V} \mathrm{PV}$ arrays output into $312 \mathrm{~V} \mathrm{DC}$, which is then transformed into line frequency $(50 \mathrm{~Hz})$ sinusoidal ac $220 \mathrm{~V} \mathrm{rms} \mathrm{voltage} \mathrm{by} \mathrm{the} \mathrm{inverter} \mathrm{and} \mathrm{thereby} \mathrm{reducing} \mathrm{the} \mathrm{system} \mathrm{losses} \mathrm{and} \mathrm{ensures} \mathrm{high} \mathrm{voltage}$ gain and higher efficiency output. The simulation results show that the proposed grid connected photovoltaic inverter trace the maximum point of solar cell array power and then converts it to a high quality ripple free sinusoidal ac power with a voltage THD below $8 \%$. The simulation also confirms the proposed photovoltaic inverter can be applied as a GTI and able to supplies the AC power to utility grid line.

\section{REFERENCES}

[1] Hiren Patel and Vivek Agarwal " MATLAB-Based Modeling to Study the Effects of Partial Shading on PV Array Characteristics", IEEE TRANSACTIONS ON ENERGY CONVERSION, VOL. 23, NO. 1, MARCH 2008

[2] Marcelo G. Villalva, Ernesto Ruppert F,“ Analysis and Simulation of the P\&O MPPT

Algorithm Using a Linearized PV Array Model”, 978-1-4244-4649-0/09/\$25.00 @2009 IEEE

[3] Aron P. Dobos, "Modeling of Annual DC Energy Losses due to Off Maximum Power

Point Operation in PV Arrays", 978-1-4673-0066-7/12/\$26.00 @2011 IEEE

[4] R.Chedid, R.Tajeddine, F. Chaaban and R. Ghajar,“ Modeling and Simulation of PV Arrays under Varying Conditions”,978-1-4799-2337$3 / 14 / \$ 31.00 \odot 2014$ IEEE

[5] Jaime Alonso-Martínez, Santiago Arnaltes, “ A Three-Phase Grid-Connected Inverter for Photovoltaic Applications Using Fuzzy MPPT”, Dpt. of Electrical Engineering, Univ. Carlos III de Madrid

[6] Ben York and Wensong Yu, " An Integrated Boost Resonant Converter for Photovoltaic Applications", IEEE TRANSACTIONS ON POWER ELECTRONICS, VOL. 28, NO. 3, MARCH 2013

[7] Hongrae Kim,Babak Parkhideh, Tim D. Bongers and Heng Gao "Reconfigurable Solar Converter: A Single-Stage Power Conversion PVBattery System”, IEEE TRANSACTIONS ON POWER ELECTRONICS, VOL. 28, NO. 8, AUGUST 2013 


\section{International Journal of Advanced Research in Electrical, Electronics and Instrumentation Engineering}

(An ISO 3297: 2007 Certified Organization)

Vol. 4, I ssue 2, February 2015

\section{BIOGRAPHY}

Almas Hossain Mollah was born in West Bengal, India on April 4, 1991. He has received his B.Tech degree in Electrical Engineering from Netaji Subhash Engineering College Kolkata West Bengal in 2012. Currently he is persuing hisM.Tech degree in Power Electronics and Drives from Jalpaiguri Govt.EngineeringCollege,Jalpaiguri,WestBengal

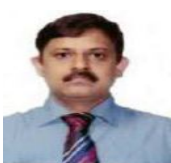

Auditor.

Prof.Gautam Kumar Panda, Professor and Head, Department of Electrical Engineering, Department of Electrical Engineering, Jalpaiguri Government Engineering College, Jalpaiguri,WB- 735102,BE (Electrical) from J.G.E. College, Jalpaiguri, M.E.E(Electrical) Specialization: Electrical Machines \& drives from JadavpurUniversity.PhD from University of North Bengal. FIE, MISTE, Certified Energy

Prof.Pradip Kumar Saha, Professor, Jalpaiguri Government Engineering College, Jalpaiguri,WB- 735102. BE (Electrical) from B.E. College, Shibpore. M.Tech((Electrical) Specialization: Machine Drives \& Power Electronics from IIT- Kharagpur.PhD from University of North Bengal. FIE, MISTE, Certified Energy Auditor 